REVIEW

\title{
Damage control approach to refractory neurogenic shock: a new proposal to a well-established algorithm
}

\section{El control de daños en el choque neurogénico refractario: propuesta de un nuevo algoritmo de manejo}

Michael W. Parra, ${ }^{(1 D}$ Carlos A. Ordoñez, ${ }^{2,3,4}$ David Mejia, ${ }^{5,6}$ (D) Yaset Caicedo, ${ }^{7}$ Javier Mauricio Lobato, ${ }^{8}$ Oscar Javier Castro, ${ }^{8}$ (D) Jose Alfonso Uribe, ${ }^{8}$ (D) Fernando Velásquez ${ }^{8}$ (iD ordonezcarlosa@gmail.com, carlos.ordonez@fvl.org.co

1 Broward General Level I Trauma Center, Department of Trauma Critical Care, Fort Lauderdale, FL USA, 2 Fundación Valle del Lili. Department of Surgery. Division of Trauma and Acute Care Surgery, Cali, Colombia., 3 Universidad del Valle, Facultad de Salud, Escuela de Medicina, Department of Surgery. Division of Trauma and Acute Care Surgery, Cali, Colombia., 4 Universidad Icesi, Cali, Colombia. , 5 Hospital Pablo Tobon Uribe, Department of Surgery, Medellin, Colombia., 6 Universidad de Antioquia, Department of Surgery, Medellin, Colombia. , 7 Fundación Valle del Lili, Centro de Investigaciones Clínicas (CIC), Cali, Colombia 8 Fundacion Valle del Lili, Department of Neurosurgery, Cali, Colombia.

\section{Abstract}

Resuscitative endovascular balloon occlusion of the aorta (REBOA) is commonly used as an adjunct to resuscitation and bridge to definitive control of non-compressible torso hemorrhage in patients with hemorrhagic shock. It has also been performed for patients with neurogenic shock to support the central aortic pressure necessary for cerebral, coronary and spinal cord perfusion. Although volume replacement and vasopressors are the cornerstones of the management of neurogenic shock, we believe that a REBOA can be used as an adjunct in carefully selected cases to prevent prolonged hypotension and the risk of further anoxic spinal cord injury. This manuscript aims to propose a new damage control algorithmic approach to refractory neurogenic shock that includes the use of a REBOA in Zone 3. There are still unanswered questions on spinal cord perfusion and functional outcomes using a REBOA in Zone 3 in trauma patients with refractory neurogenic shock. However, we believe that its use in these case scenarios can be beneficial to the overall outcome of these patients.
Palabras clave:

Cirugía de Control de Daños, Choque Neurogénico, REBOA, Algoritmo 
Copyright: @ 2021 Universidad del Valle (c) (1) $(-)$

Conflicts of interest:

The authors declare that they have no conflict of interest

Corresponding author:

Carlos A. Ordonez, MD, FACS. Division of Trauma and Acute Care Surgery, Department of Surgery.

Fundación Valle del Lili. Cali, Colombia; Division of Trauma and Acute Care Surgery, Department of Surgery, Universidad del Valle, Cali, Colombia Universidad Icesi, Cali, Colombia. Email: ordonezcarlosa@gmail.com, carlos.ordonez@fvl.org.co

\section{Resumen}

El Balón de Resucitación Endovascular de Oclusión Aórtica (REBOA) se utiliza habitualmente como complemento de la reanimación y como puente para el control definitivo de la hemorragia no compresible del torso en pacientes con shock hemorrágico. También se ha implementado en pacientes con choque neurogénico para mantener la presión aórtica central necesaria para la perfusión cerebral, coronaria y de la médula espinal. Aunque la reanimación hídrica y el uso de vasopresores son los pilares en el manejo del choque neurogénico, el REBOA puede utilizarse como complemento en casos cuidadosamente seleccionados para evitar la hipotensión prolongada y el riesgo de una lesión medular anóxica mayor. El objetivo de este artículo es proponer un algoritmo para el abordaje y manejo del choque neurogénico refractario que incluye el uso del REBOA en Zona III como estrategia para el control de daños. Todavía existen interrogantes respecto a la perfusión de la médula espinal y aún se cuestionan los resultados funcionales con el uso del REBOA en pacientes con trauma y choque neurogénico refractario. No obstante, se cree que el uso adecuado del REBOA en determinados escenarios puede mejorar los resultados globales de estos pacientes.

\section{Remark}

\section{1) Why was this study conducted?}

The objective of this manuscript is to propose a new damage control algorithmic approach to refractory neurogenic shock that includes the use of a REBOA in Zone 3.

\section{2) What were the most relevant results of the study?}

There are still unanswered questions on spinal cord perfusion and functional outcomes with the use of a REBOA in Zone 3 in trauma patients with refractory neurogenic shock. But it is our belief that its judicial use in these case scenarios can be beneficial to the overall outcome of these patients.

\section{3) What do these results contribute?}

REBOA can be used in the management of patients with refractory neurogenic shock. 


\section{Introduction}

Neurogenic shock is a loss of vasomotor tone and sympathetic innervation to the heart and peripheral vessels due to cervical or upper thoracic spinal cord injury. (T6 and above) ${ }^{1}$. The resultant impairment of the descending sympathetic pathways causes vasodilatation of visceral and peripheral blood vessels, pooling of blood, and, consequently, hypotension ${ }^{2}$. Also, loss of sympathetic innervation to the heart can cause bradycardia and/or the inability to mount a tachycardic response to hypovolemia. The physiologic effects of neurogenic shock are usually reversed with fluid resuscitation initially, followed by the judicious use of vasopressors when needed ${ }^{2,3}$. This manuscript aims to propose a new damage control algorithmic approach to refractory neurogenic shock that includes the use of a REBOA in Zone 3. This proposal is the result of the experience earned during the past 30 years in trauma critical care management of the severely injured patient from the Trauma and Emergency Surgery Group (CTE) of Cali, Colombia, which is made up of experts from the University Hospital del Valle "Evaristo García," the University Hospital Fundación Valle del Lili, the Universidad del Valle and Universidad Icesi, the Asociación Colombiana de Cirugía, the Pan-American Trauma Society and the collaboration of international specialists from the United States of America.

\section{Refractory Neurogenic Shock}

Resuscitative endovascular balloon occlusion of the aorta (REBOA) is commonly used as an adjunct to resuscitation and bridge to definitive control of non-compressible torso hemorrhage in patients with hemorrhagic shock ${ }^{4,5}$. It has also been performed for patients with neurogenic shock to support the central aortic pressure necessary for cerebral, coronary, and spinal cord perfusion ${ }^{6}$. Gray et al. reported a case of successful REBOA in a patient with neurogenic shock secondary to a comminuted fracture at $\mathrm{C} 5$ with cord contusion. This case is the first report of the use of REBOA for neurogenic shock in a trauma patient. The patient presented after a motorcycle accident with altered mental status and hypotension. The patient was initially resuscitated with blood products and vasopressors. Then, the REBOA was used as an adjunct to maintaining cardiac, cerebral and spinal cord perfusion ${ }^{7}$. Besides this case report, there is no clear consensus on REBOA as an adjunct for patients with neurogenic shock resulting from a traumatic spine injury. The concomitant physiological effects of the use of a REBOA in these specific case scenarios are still unclear. Although volume replacement and vasopressors are the cornerstones of the management of neurogenic shock, we believe that REBOA can be used as an adjunct in carefully selected cases to prevent prolonged hypotension and the risk of further anoxic spinal cord injury. For these reasons, we propose the following newly developed damage control stepwise approach to refractory traumatic neurogenic shock (Figure 1):

- STEP 1: Attention should be directed towards identifying all immediate lifethreatening injuries following the ABCDE mnemonic of ATLS ${ }^{8}$. General management of spine and spinal cord trauma, which includes restricting spinal motion. This is accomplished simply by laying the patient supine without rotating or bending the spinal column on a firm surface and an appropriately sized and placed rigid cervical collar.

- $\quad$ STEP 2: All other types of shock must be ruled out, especially hypovolemic (hemorrhagic) because, in trauma patients, it is the most common form of shock and can be present in addition to neurogenic shock ${ }^{9}$.

- STEP 3: Both careful clinical examination and thorough tomographic (Computed Tomography of the $\mathrm{C} / \mathrm{T} / \mathrm{L}$ spine) assessment are critical in identifying the level of the injury ${ }^{10}$.

- STEP 4: Moderate intravenous volume replacement with intravenous fluids and/or blood products. 

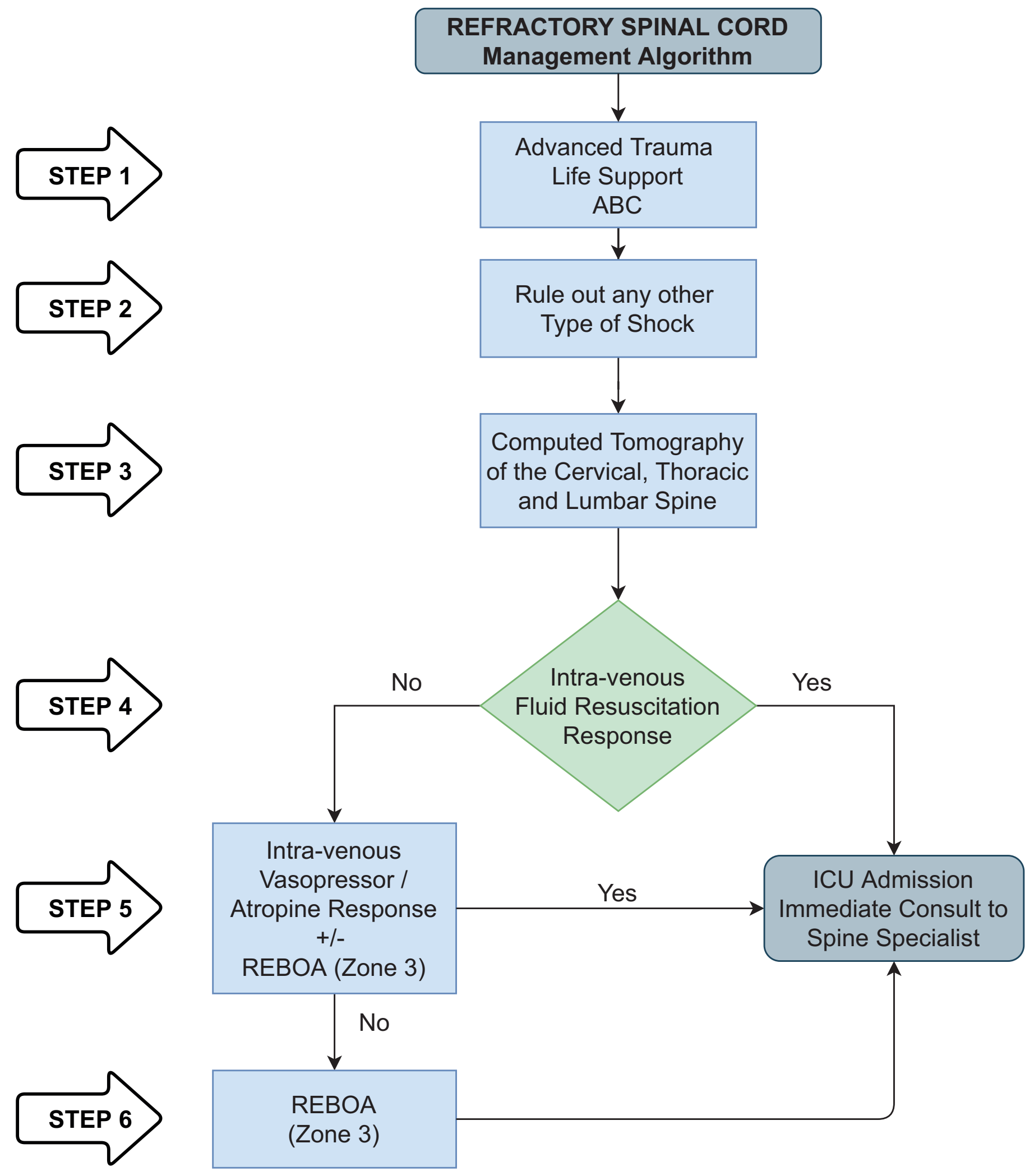

Figure 1. Refractory Neurogenic Shock Management Algorithm. 
- STEP 5: If the patient responds to initial fluid resuscitation, the patient should be admitted to the ICU and immediately consult the spine specialist. If the patient does not respond to initial fluid resuscitation, then judicious use of vasopressors should be initiated and atropine to counteract hemodynamically significant bradycardia. The use of a REBOA in Zone 3 may be used to aid in the stabilization of these patients, which can limit the amount of vasopressors required.

- $\quad$ STEP 6: If the patient's hemodynamics are refractory to intra-venous volume and vasopressor therapy, then a REBOA inflated in Zone 3 is recommended to aid in the resuscitation of the patient. Complete REBOA balloon inflation should not be used for more than 45 minutes. Then partial balloon inflation can be used to a maximum of 60 minutes ${ }^{11}$. The patient should be admitted to the ICU and immediate consult placed to the spine specialist.

\section{Complications / Discussion}

Spinal cord injury and subsequent paralysis during cross-clamping or occlusion of the thoracic aorta is a devastating complication with an overall prevalence that remains between 3 to $23 \%$, according to the current literature. An animal study in which Zone 1 REBOA were placed in primate models found that inflation times of 45-60 minutes resulted in significant clinical and histological spinal cord ischemia in 50 to $83 \%$ of cases. All spinal cord necrosis occurred in the lumbar region ${ }^{12}$. This is likely representative of the rich collateralization of vascular supply to the upper spinal cord compared to the distal ${ }^{13}$. It has been maintained that higher-level aortic occlusion portents higher risk of cord ischemia. Preventive measures of spinal cord ischemia have centered on the utilization of hypothermia and cerebrospinal fluid drainage. Unfortunately, most of these measures of spinal cord protection are not feasible in the acute trauma setting. Clinical evidence of spinal cord injury was completely mitigated in these animal studies by limiting the balloon inflation time in the thoracic aorta to a maximum of 30 minutes ${ }^{14}$. Considering all these findings, we suggest that the use of Zone 3 complete aortic occlusion with a REBOA be limited to 30 minutes in refractory cases of traumatic neurogenic shock.

Prior anatomical angiographic assessment has shown that the human body has significant intercostal-to-lumbar and/or internal mammary-to-epigastric arterial collateral blood flow and reasonable opacification of the intra-abdominal organs with a fully occlusive thoracic aortic balloon. These findings suggest the possibility of a robust collateral blood flow of the spinal cord ${ }^{11}$. The artery of Adamkiewicz (arteria radicularis magna) in humans may arise anywhere from T8 to L2 but is generally found in the T9-T12 distribution. Given that Zone 1 REBOA balloon inflation is commonly above this level this would make it prohibitive to use in refractory neurogenic shock cases and instead makes Zone 3 balloon inflation ideal because blood flow assurance will occur to the brain, heart and spinal cord via the artery of Adamkiewicz ${ }^{15}$. Zone 3 REBOA would be then protective of spinal cord injury while at the same time managing refractory hypotension from neurogenic shock.

The proposed algorithm is based on the limited evidence in the literature. Therefore, it is needed to perform research to understand the effect that REBOA can have on spinal cord perfusion and its role in the refractory neurogenic shock.

\section{Conclusion}

REBOA can be used in the management of patients with refractory neurogenic shock.

\section{References}

1. Ruiz IA, Squair JW, Phillips AA, Lukac CD, Huang D, Oxciano P, et al. Incidence and natural progression of neurogenic shock after traumatic spinal cord injury. J Neurotrauma. 2018; 35: 461-6. Doi: 10.1089/

neu.2016.4947. 
2. Fox AD. Spinal shock. Assessment \& treatment of spinal cord injuries \& neurogenic shock. JEMS. 2014; 39: 64-7.

3. Kaptanoglu L, Kurt N, Sikar HE. Current approach to liver traumas. Int J Surg. 2017; 39: 255-9. Doi: 10.1016/j.jju.2017.02.015.

4. Ordoñez CA, Parra M, Caicedo Y, Padilla N, Rodriguez F, Serna JJ, et al. REBOA as a new damage control component in hemodynamically unstable NTCH patients. Colomb Med (Cali). 2020; 51(4): e4064506

5. Ordoñez CA, Parra MW, Serna JJ, Rodríguez H F, García AF, Salcedo A, et al. Damage control resuscitation : REBOA as the new fourth pillar. Colomb Med (Cali). 2020; 51(4): e4014353. Doi: 10.25100/cm.v51i4.4353.

6. Kim DH, Chang YR, Yun J-H. Effects of resuscitative endovascular balloon occlusion of the aorta in neurotrauma: three cases. J Trauma Inj. 2020; 33: 175-80. Doi: 10.20408/jti.2020.0047.

7. Gray S, Dieudonne B. Resuscitative endovascular balloon occlusion of the aorta as an adjunct in a patient with neurogenic shock. Cureus. 2018; 10(9): e3375. Doi: 10.7759/cureus.3375.

8. The American College of Surgeons. Advanced trauma life support (ATLS) Student Course Manual. 10th Edition. United States of America: American College of Surgeons; 2018.

9. Kowalski A, Brandis D. Shock Resuscitation. Treasure Island (FL): Stat Pearls Publishing; 2021.

10. Eckert MJ, Martin MJ. Trauma: spinal cord injury. Surg Clin North Am. 2017; 97:1031-45. Doi: 10.1016/j. suc.2017.06.008.

11. Benham DA, Calvo RY, Carr MJ, Wessels LE, Schrader AJ, Lee JJ, et al. Is cerebral perfusion maintained during full and partial reboa in hemorrhagic shock conditions? J Trauma Acute Care Surg. 2021; 91(1):40-46. Doi: $10.1097 /$ TA.0000000000003124.

12. Long KN, Houston R, Watson JDB, Morrison JJ, Rasmussen TE, Propper BW, et al. Functional outcome after resuscitative endovascular balloon occlusion of the aorta of the proximal and distal thoracic aorta in a swine model of controlled hemorrhage. Ann Vasc Surg. 2015; 29: 114-21. Doi: 10.1016/j.avsg.2014.10.004.

13. Leather RP, Williams GM, Perler BA, Burdick JF, Osterman FA, Mitchell SA, et al. Angiographic localization of spinal cord blood supply and its relationship to postoperative paraplegia. J Vasc Surg. 1991; 13: 23-35. Doi: 10.1067/mva.1991.25611.

14. Eliason J, Myers D, Ghosh A, Morrison J, Mathues A, Durham L, et al. Resuscitative endovascular balloon occlusion of the aorta (REBOA): zone i balloon occlusion time affects spinal cord injury in the nonhuman primate model. Ann Surg. 2019; 274(1):e54-e61. Doi: 10.1097/SLA.0000000000003408.

15. Wadouh F, Lindemann EM, Arndt CF, Hetzer R, Borst HG. The arteria radicularis magna anterior as a decisive factor influencing spinal cord damage during aortic occlusion. J Thorac Cardiovasc Surg. 1984; 88:110 . 